\title{
Erratum to: Age-Related Changes in Collagen Properties and Mineralization in Cancellous and Cortical Bone in the Porcine Mandibular Condyle
}

\author{
Nop M. B. K. Willems · Geerling E. J. Langenbach • \\ Vincent Everts • Lars Mulder • Thorsten Grünheid • \\ Ruud A. Bank • Andrej Zentner · Theo M. G. J. van Eijden
}

Published online: 15 February 2011

(C) Springer Science+Business Media, LLC 2011

\section{Erratum to: Calcif Tissue Int (2010) 86:307-312 \\ DOI 10.1007/s00223-010-9339-2}

In our article 'Age-Related Changes in Collagen Properties and Mineralization in Cancellous and Cortical Bone in the Porcine Mandibular Condyle' (Calcif. Tissue Int. 2010 Apr; 86:307-312), we reported the abundance of Pentosidine cross-links in bone from the porcine mandibular condyle. Lately, new measurements performed on bone

The online version of the original article can be found under doi:10.1007/s00223-010-9339-2.

N. M. B. K. Willems $(\bowtie) \cdot$ T. Grünheid · A. Zentner

Department of Orthodontics, Academic Center for Dentistry

Amsterdam, University of Amsterdam and VU University,

Gustav Mahlerlaan 3004, 1081 LA Amsterdam, The Netherlands

e-mail: n.willems@acta.nl; n.m.willems@amc.uva.nl

N. M. B. K. Willems · G. E. J. Langenbach · L. Mulder ·

T. M. G. J. van Eijden

Department of Functional Anatomy, Research Institute MOVE, Academic Center for Dentistry Amsterdam, University

of Amsterdam and VU University, Gustav Mahlerlaan 3004,

1081 LA Amsterdam, The Netherlands

V. Everts · R. A. Bank

Department of Oral Cell Biology, Research Institute MOVE, Academic Center for Dentistry Amsterdam, University of Amsterdam and VU University, Gustav Mahlerlaan 3004, 1081 LA Amsterdam, The Netherlands

\section{Mulder}

Department of Biomedical Engineering, Eindhoven University

of Technology, P.O. Box 513, 5600 MB Eindhoven,

The Netherlands

R. A. Bank

TNO Quality of Life, Zernikedreef 9, 2333 CK Leiden,

The Netherlands tissue from the contralateral mandibular condyles of the same animals revealed significantly lower Pentosidine cross-links than we had originally reported. An inspection of the data published in that article reveals that the unit of measure of Pentosidine cross-links presented in Fig. 2a is incorrect. The parameter should be mmol Pentosidine per triple helix instead of mol Pentosidine per triple helix. A revised Fig. 2 is reported here. Importantly, this revision does not alter the conclusions of the article. We regret the error. 
Fig. 2 Numbers of a Pen, b HP + LP, c HP and d LP cross-links per collagen molecule as a function of age. Filled diamond cancellous bone; open triangle cortical bone. * $P<0.05$, ** $P<0.01$, *** $P<0.001$
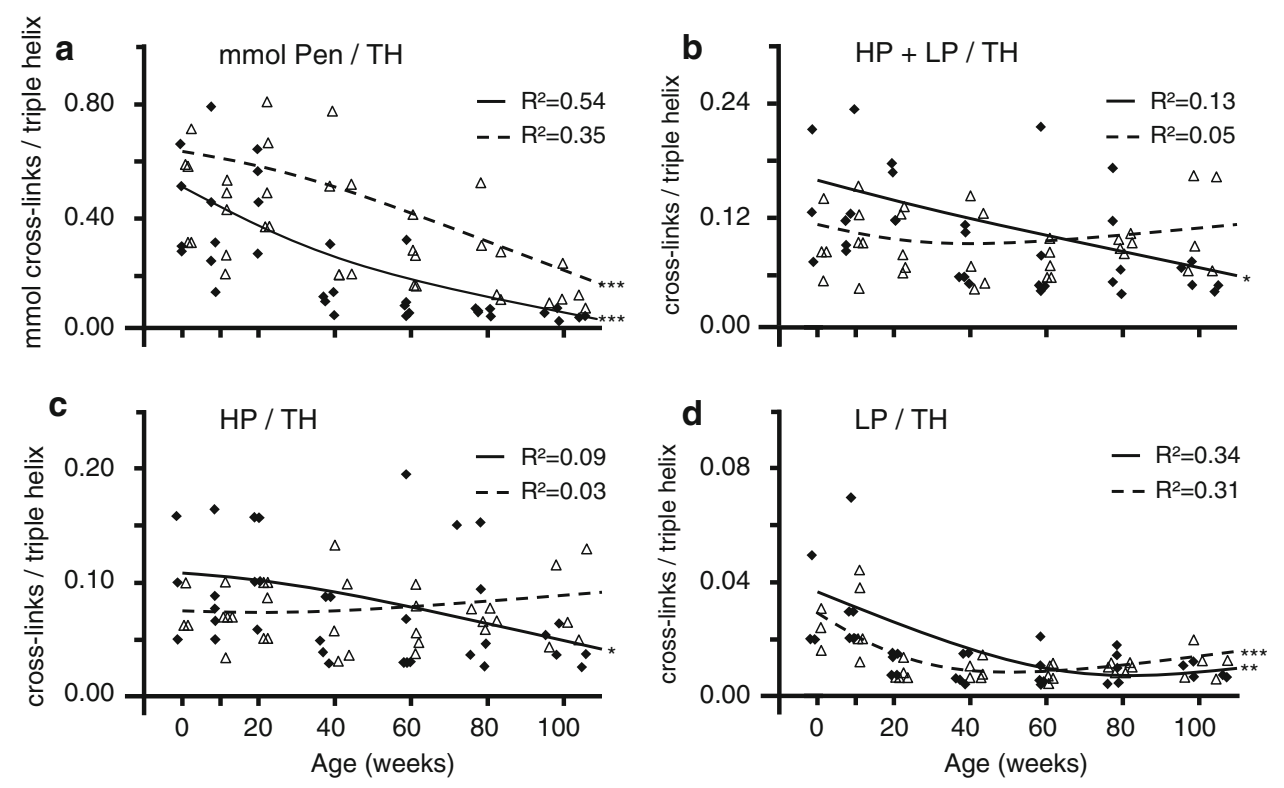